May 9;282(6275):1509-11.

30. Smithells R W, Sheppard S, Schorah C J, Seller MJ, Nevin NC, Harris R et al. Possible prevention of neural tube defects by peri-conceptional vitamin supplementation. The Lancet 1980 Feb 16;315(8164):339-40.

31. Breimer LH, Nilsson TK. Ethical stumbling blocks in uncovering folate deficiency as a preventable cause of spina bifida. Indian J Med Ethics.
2017 Oct-Dec;2(4):260-5.

32. de Jong RTH. Deliberate termination of life of newborns with spina bifida, a critical reappraisal. Childs Nerv Syst. 2008 Jan; 24(1):13-28. Discussion 29-56.

33. Almond D, Edlund L. Son-biased sex ratios in the 2000 United States census. Proc Natl Acad Sci USA. 2008 Apr 15;105(15):5681-2.

\title{
Disability activism and non-invasive prenatal testing: A response to Breimer
}

\section{ALEKSA OWEN, SATENDRA SINGH, KRISTI L KIRSCHNER}

\section{Abstract}

In his comment in IJME, Dr Breimer casts disability advocates as "special interest groups" and pits them against the abstracted concept of "women's autonomy." Against this, we assert that, far from only being a conflict of interest category, disability activism related to prenatal screening and testing is a robust part of bioethical debate and scholarship. Here, we disagree with $\mathrm{Dr}$ Breimer's characterisation of Noninvasive Prenatal Testing (NIPT) related disability activism as a threat to women's autonomy and respond to the underlying assumptions of his claims. We argue that disability need not be equated only with harm. Instead, we point out the dominant and intractable belief that disability is something to be avoided, which may lead to belief-based moral wrongs. This is the position from which disability activists make claims about the need to expand understandings of disability. Drawing on existing evidence, we find that prenatal testing does not automatically facilitate autonomy, and that NIPT may be even more of a challenge to autonomy than previous testing iterations. We suggest that NIPT should continue to be a phenomenon under close clinical scrutiny, and that ongoing debates and multiple claims-making can only add to our understanding of this phenomenon.

Keywords: non-invasive prenatal testing, disability rights, reproductive autonomy, harm principle, informed consent

Authors: Aleksa Owen (Aleksa.owen@gmail.com), Practice Fellow, Association of University Centers on Disability, Washington, DC, USA; Satendra Singh (dr.satendra@gmail.com), Associate Professor, Department of Physiology; Health Humanities Group, University College of Medical Sciences, Delhi, India; Kristi L Kirschner (kkirschn@uic.edu), Clinical Professor, Departments of Medical Education, and Neurology and Rehabilitation, and Adjunct, Department of Disability and Human Development, College of Allied Health Sciences, University of Illinois, Chicago, USA.

To cite: Owen A, Singh S, Kirschner KL. Disability activism and non-invasive prenatal testing: A response to Breimer. Indian J Med Ethics. 2020 Oct-Dec; 5(4)NS:290-3.DOI:10.20529/IJME.2020.112.

Manuscript Editor:Vijayaprasad Gopichandran

(c) Indian Journal of Medical Ethics 2020

\section{Introduction}

In his Comment published in this journal, Dr Breimer argued that disability advocates are threatening women's autonomy in the context of noninvasive prenatal testing (NIPT) (1).

Dr Breimer, here and elsewhere $(2,3)$ relegates positive views of life with disability to certain "religion and life views" (2), a viewpoint that can only be understood as a form of bias. We take issue with his assertion and rebut his conclusions here through two lines of argumentation. First, Dr Breimer's characterisation of disability advocates as impeding the technological progress toward healthier children rests, as far as we can tell, on a narrow conceptualisation of disability, specifically chromosomal anomaly, as harm. We discuss why this prevalent view of disability is problematic from the perspective of disability advocates, but also why it is the dominance of the belief itself that provides grounds for claimsmaking in favour of disability advocacy.

Second, Dr Breimer's conclusion that disability advocates are an obstacle to women's autonomy is wrong because it equates NIPT and other prenatal testing with autonomy, a relationship that may be more complicated than Dr. Breimer presents. We present evidence to back our position and conclude by suggesting that instead of assuming that more testing is an unquestionable social good, we can use NIPT and other technological medical advances to more deeply probe the social and ethical dimensions of clinical interactions and contexts.

Reproductive autonomy and disability rights need not be at odds; to pit them against each other is disingenuous and misses the core concerns of disability bioethics. Dr Breimer reduces disability advocates to special interest groups that are "anti-abortion." This is not true; many disability advocates who have critiqued prenatal testing have supported the right to abortion (4-9). We reject the notion that disability advocates are wholly trying to limit or block access to safe and affordable abortion, acknowledging that disability rights arguments have, at times, been co-opted by conservative anti-abortion positions as noted by Swaim (10). We suggest that instead of understanding disability advocacy groups as "special interest groups" infringing upon reproductive decision-making, disability bioethics arguments may re-frame 
the symbolic context of negative misunderstandings about life with disability.

\section{Against disability as harm}

We argue against the assumption that the presence of disability, operationalised in this context as a chromosomal anomaly, is automatically harmful to the child or potential child. Dr Breimer separates disability-specific eugenic selection, something he advocates for, from sex-specific eugenic selection, something he decries. This reveals his narrow view of disability as always and only a negative status and identity. Dr Breimer's arguments rest on the assumption that being born with a disability causes harm to that child, and so avoidance of disability equals avoidance of harm.

This is a well-established position among proponents of disability-selective abortion, where harm is defined as that which sets back or "frustrates" a person's interests $(11,12)$. Others have asserted that being born with a disability does not constitute a harm but does form the basis of wronging (13), which is about the violation of a person's rights. Even those who may not agree with these positions generally believe that disability may reduce quality of life.

When we consider the perspectives of people with disabilities and their families, we find that this overwhelmingly negative view of life with disability does not stand up to scrutiny. Most genetic conditions leading to disability are neither lethal nor capacity-limiting (14). Still further, in most cases, being born with a disability is not a severe or avoidable harm. Avoidance in this case would equal nonexistence, which is not preferable to life (15). Indeed, people with disabilities report higher than expected levels of life satisfaction (16-20).

The arguments that emphasise or assume disability as harm, however, also reveal the belief that people with disabilities, and specifically their existence, have lower moral value than nondisabled people (21). This view is not only prevalent in moral philosophy; evidence shows that healthcare providers demonstrate disparaging beliefs about disability (22). These disparaging beliefs have formed the basis for one of the most well-known rebuttals to the availability of and pressure to use prenatal testing, the expressivist objection. This position first put forward by Adrienne Asch and Erik Parens, states that the act of prenatal testing expresses a negative value not only towards the disabled foetus but towards existing disabled people $(23,24)$.

While the expressivist position has been critiqued, Perez Gomez' recent modified expressivist position argued that medical professionals' promotion of prenatal testing, enacts implicated negative meanings toward disability (25). Perez Gomez relies on work from Basu and Schroeder (26) to make the case that such beliefs, even when not tied to resulting actions, may still morally wrong others (25).

We have empirical and philosophical evidence that the dominant view of disability is negative and something to be avoided, which demonstrates two things. First, Perez Gomez' modified expressivist objection establishes ongoing moral wronging via implied beliefs within professionals' speech. Second, the overwhelming evidence for dominantly negative views of disability, resulting in moral wrongs, demonstrates the need for disability activists to assert their claim to rights in the prenatal testing context.

\section{Disability rights as threat to autonomy?}

Dr Breimer takes issue with disability activists speaking up because he views their priorities as a threat to women's autonomy (1). In making this claim, Dr Breimer makes two errors. First, he equates prenatal testing with increased autonomy, which may not be true. Second, he asserts that women would be pressured not to terminate a disabled foetus, when other evidence shows this to be untrue. We first provide evidence to rebut Dr. Breimer's position with respect to prenatal testing more broadly, then turn to the more recent emergence of NIPT to explore its relationship with reproductive decision-making, autonomy and informed consent.

We take issue with Dr Breimer's conclusion that in the context of prenatal testing, disability advocates are a threat to women's reproductive autonomy. Implicit within Dr Breimer's argument is that prenatal testing itself enhances autonomy, but evidence shows this is not always the case. Since the 1980s, scholars have found that women may experience pressure to have screening tests done, undergirded by the implicit assumption that they would terminate on the basis of disability (27). It's been suggested that in the 1980s, prenatal care providers increased testing offers to mitigate malpractice suits, not because patients were asking for more testing $(28,29)$. Further still, longstanding evidence shows that throughout the implementation of maternal serum screening, women have often not been provided with adequate framing to give informed consent (30-32). For instance, within clinical conversations, providers avoided content related to reproductive implications of screening, including abortion, even though such implications were the basis for informed consent (33). Evidence suggests that prenatal testing has become so routinised that women do not even know what they are testing for; it has become an unquestioned part of pregnancy (34). Autonomy, in the context of reproductive decision-making, requires decisionmaking capacity, necessary knowledge of the situation, and voluntariness. While nothing precludes prenatal testing interactions from fulfilling these conditions, evidence to the contrary also means that the offer of testing, the decision whether to test or not, and subsequent decisions about termination, do not always result in increased autonomy.

Working from his understanding of disability as a harm, $\mathrm{Dr}$ Breimer's conclusion also depends on a certain understanding of autonomy. However, the claim that disability advocates are the ones pressuring women to make decisions not to abort on the basis of disability is not accurate. It is much more likely that a pregnant woman would be pressured to terminate 
on the basis of disability $(29,35-37)$. Prenatal care providers' conversations with pregnant women impact women's decision-making (33). Moreover, providers' attitudes about disability influence how they approach these conversations $(14,22,38)$. Prenatal care providers may not have updated information regarding what life is like with a disability, or they may know but choose to withhold that information because of negative disability views (15). Providers often demonstrate disparaging attitudes towards disability within their clinical practice, particularly in the prenatal testing context (22).

\section{NIPT and autonomy}

Compared to maternal serum screening - an earlier version of prenatal screening - NIPT is more accurate and offered earlier in a pregnancy. NIPT brings new fears that misunderstandings about what NIPT is designed to detect and its limitations may result in termination based on a false positive result. Emerging evidence suggests that NIPT, in part because of its rapid clinical introduction and implementation, may make it even more challenging to ensure full autonomous informed consent (39-42). Though not common, in at least one study, $6.2 \%$ of respondents terminated on the basis of NIPT alone without waiting for confirmatory invasive testing (43). In one instance, even after an amniocentesis showed that a foetus did not have Down syndrome, a woman still terminated because the NIPT results (falsely) showed the foetus did have Down syndrome (44). This should make us view NIPT not as a solution to longstanding ethical and social challenges, but as the latest tool that serves a provocation to continue to probe these issues more deeply.

We argue that a deeper understanding of disability bioethics contributes to the possibilities of strengthening reproductive decision-making and protecting autonomy. For instance, recent evidence shows that physicians, in an attempt to facilitate better understanding of NIPT, urge their patients to decide whether they would terminate before taking the test. Yet women reported taking the test as the most important variable in making reproductive decisions (29). These mismatched expectations reveal the differential stakes in how providers present NIPT and how women perceive it. Could discussing life with disability in a more robust way within these clinical conversations change or expand awareness of or attitudes to disability?

To even ask such questions requires space to problematise the dominant moral belief that disability is always "bad and sad" (45). Disability activists demand to be a part of the conversation, seeking not just to make some kind of political gains but improve outcomes for women making reproductive decisions and for people with disabilities.

\section{Conclusion}

We should question NIPT more, not less. As medical technologies proliferate and as economic interests drive their development further, we should call for increased reflection upon emerging testing practices, more focus on parents with disabilities and other parents with diverse life experiences and locations, and a sober conversation about how families with disabilities are financially and socially supported. The empirical and moral philosophical implications of NIPT are robust and ongoing, and there is no reason to detract from or reduce their plurality. More than one thing can be true about NIPT. An example of the complex consequences of NIPT is the description of how increased NIPT uptake led to condition-specific patient advocacy groups, with no budget increases, taking on the role of providing educational and emotional support to panicked pregnant people whose physicians may not have provided such support to them in the case of a positive result (46). For these reasons, Dr Breimer's conclusion that NIPT should be considered the same as Neural Tube Defects (NTD) testing using alpha fetoprotein (AFP) is not apt because of NIPT's different context, including the commercialisation of NIPT. AFP testing has existed for decades and has been rolled into different iterations of maternal serum screening, NIPT's forerunner. Maternal serum screening exists alongside NIPT, yet as Dr Breimer himself argues (1), NIPT's uniquely aggressive commercialisation indicates there is something distinct about NIPT from maternal serum screening. For this reason, making historical and contemporary comparisons requires a careful examination of the clinical and social contours and should not be generalised, as we assert that Dr. Breimer has done in his commentary.

Here, we have provided a response to Dr Breimer's Comment in which he states that disability advocates are special interest groups who threaten women's autonomy, as evidenced by his review of NIPT-related literature. Yet we do not find that he proves his case. We disagree with his conclusion and offer two threads of argumentation, based on his assumptions about disability leading to harm, and prenatal testing leading to autonomy. We show that though the idea of disability as harm is prevalent in moral philosophy, it may be limited in actually accounting for disabled peoples' lived experiences. Still further, the dominance of that claim provides a basis for disability activists to reject that claim, in part based on the contention that beliefs, in and of themselves, may lead to moral wrongs $(25,26,47)$. We also contend that prenatal testing does not necessarily lead to women's autonomy and show that NIPT may be even more ethically challenging than previous testing options.

\section{Conflict of interest and funding support: None declared.}

\section{References}

1. Breimer LH. Non-invasive prenatal testing: Special interest groups vs women's autonomy. Indian J Med Ethics. 2020 Oct-Dec; 5(4)NS: 285-90. DOI: https://doi.org/10.20529/IJME.2020.069. Epub 2020 Jun 20.

2. Breimer LH, Nilsson TK. Ethical stumbling blocks in uncovering folate deficiency as a preventable cause of spina bifida. Indian J Med Ethics. 2017 Oct-Dec;2(4) NS:260-5.

3. Breimer LH, Nilsson TK, Breimer ME. Declarations of conflict of interest are still inadequate. Indian J Med Ethics. 2018 Jul-Sep;3(3)NS:256. Doi: https://doi.org/10.20529/IJME.2018.014

4. Asch A, Fine M. 12. Shared Dreams: A left perspective on disability rights and reproductive rights. In: Fine $M$, Asch $A$, editors. Women with Disabilities. Philadelphia: Temple university Press; 1989;297. https:// muse.jhu.edu/book/9794 
5. Hubbard R. Abortion and disability: Who should and who should not inhabit the world.. In: Davis LJ, editor. The Disability Studies Reader. New York: Routledge; 1997.pp 93-104.

6. Parens $E$, Asch A. Disability rights critique of prenatal genetic testing: reflections and recommendations. Ment Retard Dev Disabil Res Rev. 2003;9(1):40-7.

7. Briggs L, Ginsburg F, Gutiérrez ER, Petchesky R, Rapp R, Smith A, et al. Roundtable:reproductive technologies and reproductive justice. Front $J$ Women Stud.2013;34(3):102-25.

8. Jarman M.Relations of abortion:Crip approaches to reproductive justice. Fem Form. 2015;27(1):46-66. Doi:http://doi.org/10.1353/ff.2015.0008

9. Roberts D. Reproductive justice, not just rights. Dissent. 2015 Sep; 62(4):79-82.Doi: 10.1353/dss.2015.0073

10. Swaim B. Deem them not useless Washington Examiner.com. 2018 Jun 8 [cited 2020 Aug 21]. Available from: https://www.washingtonexaminer. com/weekly-standard/deem-them-not-useless

11. Bennett $R$, Harris J. Are there lives not worth living? When is it morally wrong to reproduce In: Dickenson DL, editor. Ethical issues in maternalfetal medicine. Cambridge:Cambridge University Press;2002;321-34.

12. Harris J. One principle and three fallacies of disability studies. $J$ Med Ethics. 2001 Dec;27(6):383-7.

13. Feinberg J.The moral limits of the criminal law. Oxford: Oxford University Press; 1984.

14. Wasserman D. Disability Perspectives. In: Paley Galst J, Verp M, editors. Prenatal and Preimplantation Diagnosis.Springer; 2015. p. 229-45.

15. Gould JB. Culpable ignorance, professional counselling, and selective abortion of intellectual disability. J Bioethical Inq. 2020 Jul;1-13. Doi: 10.1007/s11673-020-09984-9.

16. Gill CJ. Health professionals, disability, and assisted suicide: An examination of relevant empirical evidence and reply to Batavia. Psychol Public Policy Law. 2000;6(2):526.

17. Goering S. 'You say you're happy, but...': contested quality of life judgments in bioethics and disability studies.J Bioethical Inq. 2008;5(23):125-35.

18. Skotko BG, Levine SP, Goldstein R. Self-perceptions from people with Down syndrome. Am J Med Genet A. 2011;155(10):2360-9.

19. Albrecht GL, Devlieger PJ. The disability paradox: high quality of life against all odds. Soc Sci Med. 1999;48(8):977-988.

20. Ferguson PM. Mapping the family. In: Albrecht GL, Seelman KD, Bury, M, editors. Handb Disabil Stud. Thousand Oaks, CA: SAGE Reference; 2001. pp 239-47.

21. Bennett R. The fallacy of the principle of procreative berficence. Bioethics. 2009;23(5):265-73.

22. Klein DA.Medical disparagement of the disability experience: empirical evidence for the "expressivist objection." AJOB Prim Res. 2011;2(2):8-20.

23. Parens E, Asch A. Prenatal testing and disability rights. Georgetown, MD: Georgetown University Press; 2000.

24. Saxton M. Why members of the disability community oppose prenatal diagnosis and selective abortion. In: Parens E, Asch A, editors. Prenat Test Disabil Rights. Georgetown, MD: Georgetown University Press; 2000;147-64.

25. Perez Gomez JP. When is the Promotion of Prenatal Testing for Selective Abortion Wrong? Kennedy Inst Ethics J.2020;30(1):71-109.

26. Basu R, Schroeder M. Doxastic wronging. In: Kim B, McGrath M, editors, Pragmatic encroachment in epistemology. New York: Routledge; 2019;181-205.

27. Lippman A. Prenatal genetic testing and screening: constructing needs and reinforcing inequities. Am JL Med. 1991;17:15.

28. Löwy I. Prenatal diagnosis: The irresistible rise of the 'visible fetus.' Stud Hist Philos Sci Part C Stud Hist Philos Biol Biomed Sci. 2014;47:290-9.
29. Owen A.Cell-free DNA prenatal screening, managing chromosomal risk and distancing disability. Unpublished dissertation; 2018.

30. Constantine ML, Allyse M, Wall M, Vries RD, Rockwood TH. Imperfect informed consent for prenatal screening: Lessons from the quad screen. Clin Ethics. 2014;9(1):17-27.

31. van den Berg M, Timmermans DR, Leo P, van Vugt JM, van der Wal G. Informed decision making in the context of prenatal screening. Patient Educ Couns. 2006;63(1-2):110-117.

32. Favre R, Duchange $N$, Vayssière $C$, Kohler $M$, Bouffard N, Hunsinger M-C, et al. How important is consent in maternal serum screening for Down syndrome in France? Information and consent evaluation in maternal serum screening for Down syndrome: a French study. Prenat Diagn Publ Affil Int Soc Prenat Diagn. 2007;27(3):197-205.

33. Press $\mathrm{N}$, Browner $\mathrm{CH}$. Why women say yes to prenatal diagnosis. Soc Sci Med. 1997;45(7):979-989.

34. Gottfreðsdóttir H, Björnsdóttir K, Sandall J. How do prospective parents who decline prenatal screening account for their decision? A qualitative study. Soc Sci Med. 2009;69(2):274-277.

35. Skotko BG. Prenatally diagnosed Down syndrome: mothers who continued their pregnancies evaluate their health care providers. Am J Obstet Gynecol. 2005;192(3):670-677.

36. Kelly SE. Choosing not to choose: reproductive responses of parents of children with genetic conditions or impairments. Sociol Health IIIn. 2009;31(1):81-97.

37. Samerski S. The decision trap: Genetic education and its social consequences. Exeter, UK: Andrews UK Limited; 2015.

38. Kirschner KL, Ormond KE, Gill CJ.The impact of genetic technologies on perceptions of disability. Qual Manag Health Care. 2000;8(3):19-26.

39. Birko S, Ravitsky V, Dupras C, Le Clerc-Blain J, Lemoine M-E, Affdal AO, et al. The value of non-invasive prenatal testing: preferences of Canadian pregnant women, their partners, and health professionals regarding NIPT use and access. BMC Pregnancy Childbirth. 2019;19(1):1-11.

40. Kater-Kuipers A, De Beaufort ID, Galjaard R-JH, Bunnik EM. Rethinking counselling in prenatal screening: An ethical analysis of informed consent in the context of non-invasive prenatal testing (NIPT). Bioethics. Published online on April 23, 2020.DOI: 10.1111/bioe.12760

41. Hill M, Fisher J, Chitty LS, Morris S. Women's and health professionals' preferences for prenatal tests for Down syndrome: a discrete choice experiment to contrast noninvasive prenatal diagnosis with current invasive tests. Genet Med. 2012;14(11):905-913.

42. Dondorp W, De Wert G, Bombard Y, Bianchi DW, Bergmann C, Borry P, et al. Non-invasive prenatal testing for aneuploidy and beyond:challenges of responsible innovation in prenatal screening. Eur J Hum Genet. 2015;23(11):1438-1450.

43. Curnow KJ, Gross SJ, Hall MP, Stosic M, Demko Z, Zimmermann B, et al. Clinical experience and follow-up with large scale single-nucleotide polymorphism-based noninvasive prenatal aneuploidy testing. $A m \mathrm{~J}$ Obstet Gynecol. 2014;211(5):527-e1.

44. Daley B. Oversold and misunderstood. WGBH [Internet]. 2014 Dec 13 [cited 2020 Aug 24]; Available from: https://www.wgbh.org/news/ people/beth-daley

45. Charlton Jl. Nothing about us without us: Disability oppression and empowerment. Berkeley, CA:Univ of California Press; 2000.

46. Meredith S, Kaposy C, Miller VJ, Allyse M, Chandrasekharan S, Michie M, et al. Impact of the increased adoption of prenatal cfDNA screening on non-profit patient advocacy organizations in the United States. Prenat Diagn. 2016;36(8):714-719.

47. Basu R. Beliefs that wrong. Phil Topics 2018;46(1):1-18. 